\title{
The Divination of Things by Things
}

\author{
Haider Akmal \\ Lancaster University \\ Lancaster, UK \\ h.a.akmal@lancaster.ac.uk

\section{Paul Coulton} \\ Lancaster University \\ Lancaster, UK \\ p.coulton@lancaster.ac.uk
}

\begin{abstract}
As humans our view of the world is predominantly restricted to our own experience and are largely oblivious to the alternate perspective of reality experienced by the objects that cohabit our spaces even though such objects are often integral components of our lives. This paper considers the growing phenomenon whereby non-human objects such as cutlery and appliances are having what might be considered human-like experiences through integration of advanced computational programming. By examining the services provided by Madame Bitsy's Fantastic Future Forecasting and Fortune Telling Emporium for the Internet of Living Things, which is a fully autonomous online fortune telling service for Internet of Things enabled objects and services, we attempt to illuminate what it means to be a digitally connected object.
\end{abstract}

\section{Author Keywords}

Internet of Things; Tarot; Forecasting; HCI;

Philosophical Carpentry; Design Fiction

for compon this notice and the full citation on the first page. Copyrights

for components of this work owned by others than ACM must be honored.

post on servers or to redistribute to lists, requires prior specific permission

and/or a fee. Request permissions from Permissions@acm.org.

CHI'20 Extended Abstracts, April 25-30, 2020, Honolulu, HI, USA (c) 2020 Association for Computing Machinery.

ACM ISBN 978-1-4503-6819-3/20/04..\$15.00

https://doi.org/10.1145/3334480.3381823

\section{CSS Concepts}

- Human-centered computing Human computer interaction (HCI); Empirical Studies in HCI 


\section{Introduction}

Fate as a concept is prevalent in many cultures representing a philosophical school of thought whereby events and actions within our lives are deemed subject to a predetermined course or destiny ${ }^{1}$. Human history has seen its fair share of interaction with a tradition of fortune telling. Leland [11] presents a history of fortune telling with roots going into early gypsy traditions of witchcraft, shamanism, and other occult arts. So called fortune tellers have appeared in every known belief system in some form or the other often taking to different methods such as reading the stars or palms to determine causality with future events. These methods can by no means be regarded as scientific irrespective of the number of constellations and stars provoked yet their anthropological presence and affect cannot be denied. Be it Turkish coffee reading, Pakistani parrot fortune telling, or Aboriginal Dreaming Totems, they all resonate sufficiently with a certain audience that for all accounts lay their faith in these methods of divination.

Without detailing the roots of this medium, the point to note here is the mention of 'human history', not animal or plant history for till now an interest in future events or divination has always presented itself as a purely human affair. Times certainly are changing, in this research we highlight a new wave of divination dubbed Object-Oriented Fortune Telling where non-human entities are consulting with non-human fortune tellers or divinators. The rise in Internet of Things (IOT) objects has brought with it considerable advances in Machine Learning (ML) and has resulted in both IoT enabled objects seeking divinatory guidance and the

1 https://plato.stanford.edu/entries/free-will-foreknowledge/ rise of autonomous services that provide this divination.

One might reasonably ask, why would an inanimate object care about the future or even attempt to ask a question relating to their future? Surprisingly, this question is not as unanswerable as one might assume as considerable philosophical thought has gone into the consideration of what it means to be an object or thing in a human world [9] going as far back as Heideggerian Tool-Analysis. In fact, the definition of what an object is has also been expanded over time to incorporate various ideologies that themselves can be considered as objects such as, global warming through Morton's hyperobjects [15] or having cultural or social attributes through Latour's quasi-objects [10]. Recent studies in what it means to be an object connected to the Internet has become a pertinent question amongst scholars ([4], [2], [13]) trying to improve our understanding of IoT. Although the characterization of these so-called objects having agency is much more contentious ([3], [8], [16]). Whilst accepting such debate it is also apparent ML has developed such that our non-human tools, assets, and services have been augmented to such an extent that they are further fuel for these philosophical debates. Where once the human was regarded as the principle source of all knowledge and information creation or gathering, today $M L$ is often hailed as providing the new frontier for such activities.

Where the sight of a fortune teller in a carnival, back alley, or high street was once quite unsurprising it was relatively a niche activity but the development of the Internet has provided a new platform for propagating these services more widely. A search of the Android Play Store for the terms 'fortune telling' and 'psychic' 
reveals more than 150,000 applications that in some form attempt divination through software for users often through subscription-based models. One particular application is Madame Bitsy's Fantastic Future Forecasting and Fortune Telling Emporium for the Internet of Living Things. Unlike other applications claiming psychic prowess that target humans, Madame Bitsy's clientele are IoT enabled objects and services. The intention here being to provide human readable forecasting of futures for human cohabiters of digitally empowered IoT objects.

\section{Programmed Foresight}

Madame Bitsy is not human, she is an autonomous agent created by software start-up Gaaps who specialize in creating applications that use IoT in provocative ways. Gaaps emerged through a collaboration between Lancaster University's computing students from InfoLab and design students from Imagination Lancaster with the purpose of addressing the UKs industrial strategy for commercialization of university research. Though other notable projects also exist from the start-up, Madame Bitsy stands out having garnered considerable media attention along with her commercial success (Figure 1). The official description on the Play Store page presents her as a real person delivering bespoken Tarot readings for her clients described as part of the Internet of Living Things. Immediately our non-human objects are given life through this non-human avatar but what happens next is where the interaction between human/nonhuman becomes more interesting. Before proceeding and for the sake of clarity throughout this paper Madame Bitsy will be referred to as a real person.

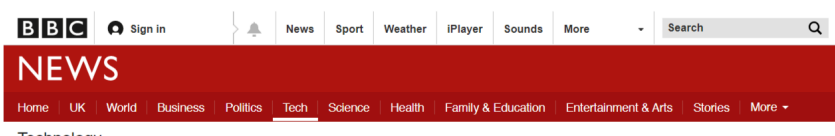

$\underline{\text { Technology }}$

Fortune telling app for smart devices becomes highest grossing app on AppStore

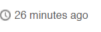

$f \circ \square<$ share

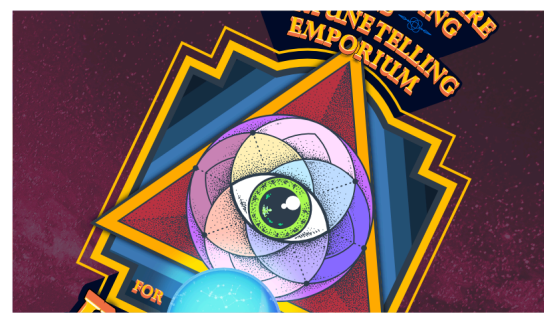

Top Stories

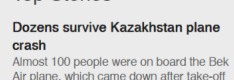

Q 2 hours ago

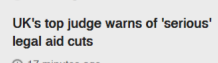

escalate bushnfics

Features

कित

Figure 1 Madame Bitsy's uniqueness gave the topic of alternative fortune telling news attention

Lifting the Veil

The Fantastic Future Forecasting and Fortune Telling Emporium is a mobile application that runs on a human cohabiters' mobile device. It requires the human to provide access for Madame Bitsy to any IoT enabled devices around them whereby it then initiates its divination which is independent of the human. A human-readable translation is provided at the end of the session after consent from Madame Bitsy's client. This provided reading is through a bespoke Tarot deck designed specifically for the IoT. The reading of Tarot comes by articulating a story from the cards placed in the traditional manner which is dictated by the divinatory (Madame Bitsy). This bespoken Tarot deck consists of a condensed form of Tarot presented through keywords that each card depicts presented in a unique $M L$ language which the device can understand and perhaps act upon (or at least that is the intention). 
The human-readable version is presented with a human orientated perspective.

The application does this by giving a connected device access to its own programming creating an intimate link between the two. Traditionally this link is done in person between psychic and client and begins with the shuffling of the Tarot deck by the client. In this case the shuffling is done by the device through a series of pings between itself and Madame Bitsy. Once the digital deck is shuffled the cards are revealed to the device which in turn after processing provides a 'response'.
The response returned in the same language is further articulated for the human user and presented via the mobile application interface.

The result is a compelling translation of whatever 'conversation' happened between Madame Bitsy and her client. It is possible the device struggled in its response time or presented Bitsy with obscure data meaning the translation is not always easily understandable by a human. To further illuminate this activity, we will present an example of a forecast requested by an IoT Smart Fork (Figure 2 ).

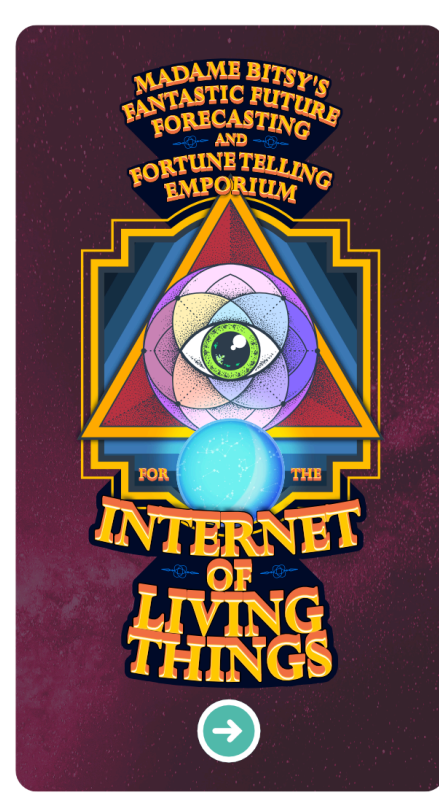

a

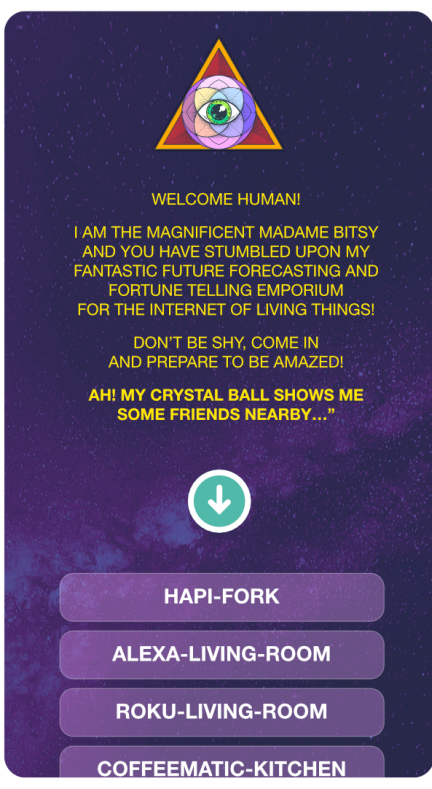

b

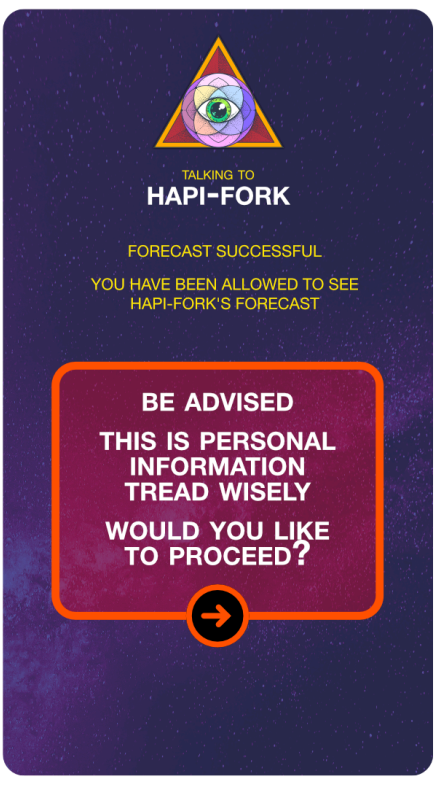

C

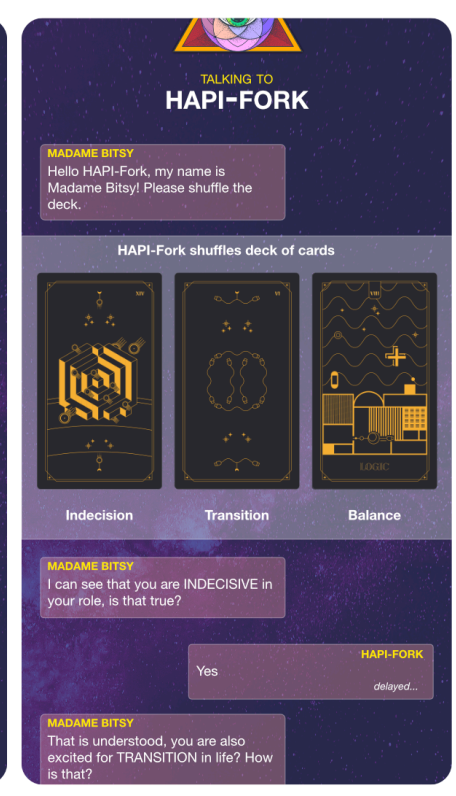

d

Figure 2 Screens showing our requested forecast from the Madame Bitsy app for the HAPI-Fork an IoT enabled smart fork 
Telling the future of a Smart Fork

This particular smart fork (HAPI-FORK) in question is intended to track usage data in the form of eating behaviors-speed of eating to be precise. In turn it gives the user haptic feedback to what it considers a bad eating habit in hopes for the user to correct themselves. A simple design with a simple purpose. We began by starting the app on a mobile phone (Figure $2 \mathrm{~b})$ and were received with the following message:

"Welcome Human! I am the Magnificent Madame Bitsy and you have stumbled upon my Fantastic Future Forecasting and Fortune Telling Emporium for the Internet of Living Things! Don't be shy, come in and prepare to be amazed! Ah! My crystal ball shows me some friends nearby..."

The app has already begun presenting itself as a person and follows up with a list of connectable IoT objects nearby. Upon selecting the HAPI-Fork the app begins the pinging and processing between itself and the fork. After a short while Madame Bitsy reveals what she has found ironically with a disclaimer that the information provided is of a personal nature for the fork and is shown through their permission (Figure 2c). The granting of this permission makes us wonder if its future implementations will allow a device to deny its human owner the right to see its forecast.

The forecast is presented as a discourse between her and the fork starting off with the revealed cards and their keywords (Figure 2d). In our case the fork extracted the cards Logic, Six of Cables, and Programmer of Sensors. As these cards are appropriations of traditional Tarot cards, they take on the same naming sensibility with their meaning juxtaposed to near equivalents in IoT. The app then presents us the keywords associated with these cards: Indecision, Transition, and Balance respectively.

Following this is a translation of the conversation in a ML language between Bitsy and the fork presented as a discussion between psychic and client.

Madame Bitsy: Hello HAPI-Fork, my name is Madame Bitsy! Please shuffle the deck.

HAPI-Fork: (shuffling)

Madame Bitsy: (Reveals cards) I can see that you are Indecisive in your role, is that true?

HAPI-Fork: (delayed response) Yes.

Madame Bitsy: That is understood, you are also excited for a Transition in life? How is that?

HAPI-Fork: I pick food more.

Madame Bitsy: The Programmer of Sensors means you are emotionally Balanced, is that true?

HAPI-Fork: Negative.

Madame Bitsy: Would you like your human owner to read this?

HAPI-Fork: Yes.

This discussion though imperfect presents an interesting dialogue between two non-human entities. One might be compelled to nudge it further and wonder what the fork meant by not being 'emotionally balanced' or how it was 'indecisive' in its role. The forecast goes on to include a response from Madame Bitsy to the user which is possibly defined through equal parts logic and script. The message received from her paints a picture of an indecisive 'fork' with intentions of evolving further (whatever that might mean) and includes towards the end mention of this message having been forwarded to the device as well. 
It is yet to see our smart fork take any action upon her forecast.

Carpentry: In his book Alien Phenomenology Ian Bogost defines the idea of Carpentry as the crafting of artifacts for practicing philosophical arguments equating it to "philosophical lab equipment" [4]. Among examples of carpentered artifacts he presents the Latour Litanizer. A script that takes entries from Wikipedia and presents them as ontographs or descriptions of their realities. This creates tiny universes or flat ontologies a concept used in explaining the phenomenon of objectoriented ontology.

\section{Discussion}

This entire experience of fortune telling for non-human entities could be seen as a way to further philosophical discussions around object-oriented perspectives as presented by philosophers such as Graham Harman and Levi Bryant. Whether the forecasting of any kind of futures for non-human objects could be considered a matter of concern within a scholarly debate be it in technology, design, philosophy, anthropology, etc. is yet to be seen. We do not assert the possibility of agency within IoT devices that are capable of learning through experience such as a smart fork, this study is meant to be seen as a point for further discourse.

Could this software be considered a mobile game? This question may arise particularly as a human interface is presented for an activity designed with non-human in mind. But artefacts such as Madame Bitsy could also fall under the category of Carpentry as defined by Ian Bogost [4]. Bogost defines carpentry as a way to "do philosophy" through the creation of philosophically charged artifacts. In many ways, Madame Bitsy does provoke a philosophical debate around the presence of objects in our vicinity especially with interactions like these suggesting our IOT objects have taken on alternate personas and abilities. Alternatively, the software also presents an opportunity to raise odd questions on designed objects such as what makes a smart fork want to be more or what comes next in the evolution of a fork when a smart fork can exist? The use of this knowledge within fields of design and technology could open doors for further research and the design of products by considering alternative perspectives; in this case the perspective of the product rather than the user.

\section{Conclusion}

This paper presented a design fiction built around the Tarot of Things [12] an extension of a study in alternative perspectives for the design of Human Computer Interaction ( $\mathrm{HCI}$ ) being conducted at Lancaster University [7]. All artefacts described within the paper with the notable exception of the bespoke IoT Tarot cards are works of fiction created using the concept of world building as defined by Coulton et al. [6] with the intention of ushering a debate into the view of non-human perspectives in the design of IoT enabled systems. The research furthers earlier works ([1], [2], [12], [14]) in the use of Object-Oriented Ontology (OOO) as a means to approach the design of IoT enabled objects through a philosophical lens whereby questioning established human-centered design approaches for technology.

The Tarot of Things is designed in Python and used to extract on-request Tarot readings of IoT interactions with the intention of it being linked with said devices. It does this by simplifying Tarot descriptions to keywords ${ }^{2}$ which can be interpreted in the manner of a flat ontology.

The world defined in this paper attempts to envision this scenario focusing on a potential for 'seeing through the eyes' of an IoT enabled object in a postanthropocentric [13] view of IOT. The use of Tarot in

2 A complete list of keywords is presented at the end in Tables 15 with the cards and playable digital variant of the game online at http://www.fictionware.org/tarot-of-things/ 
this regard is less as a means for prediction and more in line with Tarot for unveiling unconscious material as a "projective hypothesis" [5] for the design of IoT systems. Through such attempts the hope is of furthering research into not only philosophical carpentry but also alternative design methodologies that may consider non-linear perspectives of design within IoT systems.

\section{References}

[1] Haider Akmal, Paul Coulton. 2018. Using Heterotopias to Characterise Interactions in Physical/Digital Spaces. In Proceedings of DRS2018 Limerick. 1, 296-278. https://doi.org/10.21606/dma.2017.348

[2] Haider Akmal, Paul Coulton. 2019. Research Through Board Game Design. In Proceedings of RtD 2019: Method \& Critique.

https://doi.org/10.6084/m9.figshare.7855808.v1

[3] John M. Bishop. 2002. Dancing with pixies: Strong artificial intelligence and panpsychism.

[4] Ian Bogost. 2012. Alien Phenomenology, or, What it's like to be a thing. University of Minnesota Press, Minneapolis.

[5] Inna Semetsky. 2006. Tarot as a projective technique. Spirituality and Health International, 7, 4: 187-197. https://doi.org/10.1002/shi.252

[6] Paul Coulton, Joseph G. Lindley, Miriam Sturdee, Mike Stead. 2017. Design fiction as world building. In Proceedings of RtD 2017. https://figshare.com/articles/Design_Fiction_as_W orld_Building/4746964

[7] Paul Coulton, Joseph G. Lindley, 2019. More-Than Human Centred Design: Considering Things. The Design Journal 22, 4: 463-481. https://doi.org/10.1080/14606925.2019.1614320
[8] Gordana Dodig-Crnkovic, Rickard von Haugwitz. 2017. Reality construction in cognitive agents through processes of info-computation. In Representation and Reality in Humans, Other Living Organisims and Intelligent Machines. Springer.

[9] Graham Harman. 2011. The quadruple object. Zero Books, Washington.

[10] Bruno Latour. 1994. We have never been modern. Harvard University Press, Massachusetts.

[11] Charles G. Leland. 2007. Gypsy sorcery and fortune telling. Cosimo, Inc, New York.

[12] Joseph Lindley, Haider A. Akmal, Paul Coulton. 2020. Design Research and Object-Oriented Ontology. Open Philosophy, 3, 1: 11-41. https://doi.org/10.1515/opphil-2020-0002

[13] Joseph Lindley, Paul Coulton, Hayley Alter. 2019. Networking with Ghosts in the Machine: Speaking to the Internet of Things. The Design Journal 22, sup1, 1187-1199. https://doi.org/10.1080/14606925.2019.1594984

[14] Joseph Lindley, Paul Coulton, Rachel Cooper. 2017. Why the Internet of Things needs Object Oriented Ontology. The Design Journal 20, sup1, S2856-S2857. https://doi.org/10.1080/14606925.2017.1352796

[15] Timothy Morton. 2013. Hyperobjects: Philosophy and Ecology after the End of the World. University of Minnesota Press, Minneapolis.

[16] Mathew T. Segall. 2011. Cosmos, Anthropos, and Theos in Harman, Teilhard, and Whitehead.

Retrieved December 20, 2019 from https://footnotes2plato.com/2011/07/12/cosmosanthropos-and-theos-in-harman-teilhard-andwhitehead/ 
Tarot of Things referenced a standard Rider-Waite Tarot deck appropriated to IoT. The complete deck and playable digital game is available online.

\begin{tabular}{|c|c|}
\hline Card Name & Keywords \\
\hline The User & Innocence, Wonder, Foolishness; Taken Advantage, Recklessness \\
\hline The Program & Structure, Authority; Chaos, Domination \\
\hline The Network & Nurturing; Excess \\
\hline The Operating System & Legacy; Servitude \\
\hline The Programmer & Creation, Adaption; Cunning, Deception \\
\hline Data & Playfulness, Addiction; Restoring Control \\
\hline The Connection & Conviction; Doubt \\
\hline Assistant & Wisdom, Unconscious; Repression, Secrets, Hidden Agendas \\
\hline Logic & Choices; Indecision \\
\hline Idle & Insight; Isolation \\
\hline Time & Patience; Excess \\
\hline Cables & Discipline; Loss of Direction \\
\hline Disconnection & Release; Stalling \\
\hline Termination & Change, Metamorphosis; Stagnation, Decay \\
\hline Gateway & Courage; Reckoning \\
\hline The Hacker & Disaster; Disaster Avoided \\
\hline The Server & Pleasure; Negativity \\
\hline Deep Learning & Intuition, Wisdom; Secrets \\
\hline Node & Rejuvenation; Insecurity \\
\hline Logs & Illusions, Unclarity; Misinterpretation \\
\hline Loop & Fate, Karma; Lack of Control \\
\hline Thing & Reflection; Doubt \\
\hline The Constellation & Harmony; Incompletion \\
\hline
\end{tabular}

Table 1: List of bespoke Major Arcana cards for Tarot of Things. The cards were created by simplifying descriptions of standard Tarot cards by equating them to a close approximation of IoT. Keywords were extracted from the simplification and presented for both right-side up orientation and up-side down (red) 


\begin{tabular}{c|c} 
Card Name & $\begin{array}{c}\text { Keywords } \\
\text { Ace of Chips }\end{array}$ \\
\hline Two of Chips & $\begin{array}{c}\text { Making Decision; } \\
\text { Bad Planning }\end{array}$ \\
\hline Three of Chips & Expansion; Delays \\
\hline Four of Chips & Community; Transience \\
\hline Five of Chips & Conflict; Avoiding Conflict \\
\hline Six of Chips & Success; Lack of Recognition \\
\hline Seven of Chips & Perseverance; Overwhelmed \\
\hline Eight of Chips & Movement; Panic \\
\hline Nine of Chips & Resilience; Fatigue \\
\hline Ten of Chips & Responsibility; Stressed \\
\hline Assistant of Chips & Exploration; Procrastination \\
\hline User of Chips & Adventure; Recklessness \\
\hline Network of Chips & Determination; Jealousy \\
\hline Programmer of Chips & Big Picture; Impulsive
\end{tabular}

Table 2: List of bespoke Suite of Chips cards for Tarot of Things. The Suite of Chips was created in place of the standard Suite of Wands in a Tarot deck. The names were defined to suit better to IoT. Keywords are presented for both right-side up orientation and up-side down (red)

\begin{tabular}{|c|c|}
\hline Card Name & Keywords \\
\hline Ace of Clouds & Discipline; Manipulative \\
\hline Two of Clouds & $\begin{array}{c}\text { Adaption; } \\
\text { Disorganized, Overwhelmed }\end{array}$ \\
\hline Three of Clouds & $\begin{array}{l}\text { Teamwork, Collaboration; } \\
\text { Disorganized, Group Conflict }\end{array}$ \\
\hline Four of Clouds & $\begin{array}{l}\text { Conversation, Frugality; } \\
\text { Greediness, Possessiveness }\end{array}$ \\
\hline Five of Clouds & $\begin{array}{l}\text { Need, Insecurity; } \\
\text { Insecurity }\end{array}$ \\
\hline Six of Clouds & Sharing; Power, Domination \\
\hline Seven of Clouds & Perseverance; Distractions \\
\hline Eight of Clouds & High Standards; Uninspired \\
\hline Nine of Clouds & Rewards; Obsession \\
\hline Ten of Clouds & $\begin{array}{l}\text { Culmination; } \\
\text { Lack of Resources }\end{array}$ \\
\hline Assistant of Clouds & Diligence; Laziness \\
\hline User of Clouds & Efficiency; Obsessiveness \\
\hline Network of Clouds & $\begin{array}{l}\text { Practicality, Security; } \\
\text { Self-Centeredness }\end{array}$ \\
\hline $\begin{array}{l}\text { Programmer of } \\
\text { Clouds }\end{array}$ & Abundance; Excess \\
\hline
\end{tabular}

Table 3: List of bespoke Suite of Clouds cards for Tarot of Things. The Suite of Chips was created in place of the standard Suite of Pentacles in a Tarot deck. The names were defined to suit better to IoT. Keywords are presented for both right-side up orientation and up-side down (red) 


\begin{tabular}{c|c} 
Card Name & Keywords \\
\hline Ace of Sensors & Intuition; Emptiness \\
\hline Two of Sensors & $\begin{array}{c}\text { Connection; } \\
\text { Broken Communication }\end{array}$ \\
\hline Three of Sensors & Community; Overindulgence \\
\hline Four of Sensors & Apathy; Awareness \\
\hline Five of Sensors & Disappointment; Acceptance \\
\hline Six of Sensors & Memories; Independence \\
\hline Seven of Sensors & \begin{tabular}{c} 
Daydreaming; \\
\hline Eight of Sensors
\end{tabular} \\
\hline Nine of Sensors & Disillusionment; Avoidance \\
\hline Ten of Sensors & Satisfaction; Dissatisfaction \\
\hline Assistant of Sensors & Fulfilment; Broken \\
\hline User of Sensors & Sensitivity; Insecurity \\
\hline Network of Sensors & Calm; Dependence \\
\hline Programmer of & Balance; Coldness \\
\hline Sensors &
\end{tabular}

Table 4: List of bespoke Suite of Sensors cards for Tarot of Things. The Suite of Sensors was created in place of the standard Suite of Cups in a Tarot deck. The names were defined to suit better to IoT. Keywords are presented for both right-side up orientation and up-side down (red)

\begin{tabular}{c|c} 
Card Name & Keywords \\
\hline Ace of Cables & Clarity; Chaos \\
\hline Two of Cables & Stalemate; Indecision \\
\hline Three of Cables & Suffering; Recovery \\
\hline Four of Cables & Restoration; Stress \\
\hline Five of Cables & Sneakiness; \\
\hline Six of Cables & Transition; Unresolved Issues \\
\hline Seven of Cables & Trickery; Rethinking \\
\hline Eight of Cables & Imprisonment; Freedom \\
\hline Nine of Cables & Anxiety; Reaching Out \\
\hline Ten of Cables & Failure; Upwards \\
\hline Assistant of Cables & Curiosity; Deception \\
\hline User of Cables & Impulsiveness; Unpredictability \\
\hline Network of Cables & Complexity, Perceptive; Cruel \\
\hline Programmer of & Discipline; Manipulative \\
\hline Cables &
\end{tabular}

Table 5: List of bespoke Suite of Cables cards for Tarot of Things. The Suite of Cables was created in place of the standard Suite of Swords in a Tarot deck. The names were defined to suit better to IoT. Keywords are presented for both right-side up orientation and up-side down (red) 